\title{
Feasibility of Kahoot! as a Real-Time Assessment Tool in (Histo-)pathology Classroom Teaching
}

This article was published in the following Dove Press journal:

Advances in Medical Education and Practice

\author{
Daniel Neureiter ${ }^{1,2}$ \\ Eckhard Klieser ${ }^{1,2}$ \\ Bettina Neumayer ${ }^{1,2}$ \\ Paul Winkelmann ${ }^{1,2}$ \\ Romana Urbas ${ }^{1,2}$ \\ Tobias Kiesslich ${ }^{3,4}$ \\ 'Institute of Pathology, Paracelsus \\ Medical University/Salzburger \\ Landeskliniken (SALK), Salzburg, Austria; \\ ${ }^{2}$ Cancer Cluster Salzburg, Institute of \\ Pathology, Paracelsus Medical Universityl \\ Salzburger Landeskliniken (SALK), \\ Salzburg, Austria; ${ }^{3}$ Department of \\ Internal Medicine I, Paracelsus Medical \\ University/Salzburger Landeskliniken \\ (SALK), Salzburg, Austria; ${ }^{4}$ Institute of \\ Physiology and Pathophysiology, \\ Paracelsus Medical University, Salzburg, \\ Austria
}

\begin{abstract}
Purpose: New technologies like gamification are continuously integrated into medical education during the last years. However, the benefit and implementation of such gaming platforms are not clearly studied. This analysis assesses the feasibility of Kahoot! regarding simplicity and low-cost performance as a learning/teaching tool for medical education in (histo-)pathology.
\end{abstract}

Materials and Methods: In this feasibility pilot study, we developed 36 modules for different benign and malignant tumors, covering four major topics: gastrointestinal tract, dermatology, urogenital tract, and hematology. Each module included histomorphological text-based questions for education of 2nd-year medical students. The online gaming-platform Kahoot! was anonymously implemented before and after "classical" medical education which included discussions of histological slides for each tumor entity using Microsoft PowerPoint-based presentations in combination with microscopical demonstrations. Participating students were invited to a seven-questions evaluation about the online educational approach.

Results: Overall, 23 of 51 students of the study class completed the pre- and the postevaluation of Kahoot! in one or more organ systems. The percentage of correct answers increased from the initial mean/median of $47.2 / 45 \%$ to $77.2 / 76.3 \%$. Simultaneously, the time for answering questions decreased by roughly $50 \%$ (from mean/median time of $9.1 / 8.3$ seconds to $5.1 / 4.3$ seconds) from pre- to post-assessment. The results were independent of gender; however, there were scoring differences between the different organ systems. Students positively evaluated the routine implementation of the gaming-platform Kahoot! within medical education.

Conclusion: Kahoot! is as a simple, direct, and low-cost application in medical teaching improving learning outcomes of pathomorphological topics with high acceptance by students. Kahoot!-based evaluations should be also performed in more advanced topics in the field of histopathology.

Keywords: education assessment, medical education, online-tools, Kahoot!, pathology

\section{Introduction}

Besides research, medical education is the main task of medical academic institutions. ${ }^{1}$ However, medical education is time-, personnel-, and costconsuming in both, under- and postgraduate programs. ${ }^{2}$ Through technological advancement, alternative didactic approaches can offer solutions in times of limited faculty resources. ${ }^{3}$ Conventional classroom lectures are still the major method in medical schools while the rising digital possibilities could fundamentally support and strengthen the medical education received by students. ${ }^{4}$ Digital educational methods range from single video tutorials to complex 3D-simulation for medical
Correspondence: Daniel Neureiter Institute of Pathology, Paracelsus Medical University/Salzburger Landeskliniken (SALK), Salzburg, Austria

Tel +43(0)5 725529027

Fax +43 (0)5 725529099

Email d.neureiter@salk.at

Advances in Medical Education and Practice 2020: I I 695-705 
procedures to improve the skills of the students. ${ }^{5}$ Another approach is learning by game-based tools, ie, "gamification". Bigdeli and Kaufmann ${ }^{6}$ have concluded that the utilization of game elements can increase user engagement. As reviewed by Johnson et $\mathrm{al}^{7}$ gamification is commonly defined as "the use of game design elements in nongame contexts". However, the acceptance of gamification as an additional tool in the medical education has been low until now. ${ }^{8}$

A systematic review analyzed whether gamification has the potential to increase students' engagement in online programs and learning tools. ${ }^{9}$ Additional investigations have shown that game-based learning has several benefits compared to conventional teaching methods. ${ }^{10,11}$ Indeed, including the concept of gamification in medical teaching could increase the motivation of the students and subsequently significantly improve learning behavior. ${ }^{12,13}$ Today, a number of software platforms are available to gamificate the course contents through online applications such as Kahoot!, Quizziz, Quizlet, and Socrative. ${ }^{14}$ In this context, Kahoot! represents a low-cost and web-based system for studying and evaluating students.

The web interface of Kahoot! started 2013 as a free education platform for teachers and students. Access is possible with all electronic devices such as mobile phones, tablet computers or desktop computers, as long as an Internet connection is established. As recently reviewed by A.I. Wang and R. Tahir in 2020 (based on Google Scholar, Science Direct, Wiley InterScience, Web of Science, Scopus) the application of Kahoot! can positively influence learning performance, classroom dynamics, students' and teachers' attitudes, and students' anxiety, whereby the specific integration of Kahoot! in corporate training or similar is missing throughout the literature. ${ }^{15}$

Another aspect of gamification is the possibility to immediately and adequately evaluate the learning outcomes. This type of assessment is time-saving compared to traditional ways in which the students' learning curve is determined by "guiding" feedback, which puts a "status quo" score up against final score of the course. ${ }^{16-18}$ Summative traditional assessments reflect the educational outcome afterwards and are less time- and cost-effective to perform data extraction and analysis to determine a teaching outcome. ${ }^{18,19}$ Kahoot! allows to record the single and summative results (correct/incorrect answers of each question with time and score points of each participant). The scores and data are stored online and can be downloaded in Excel format at any time.
Interestingly, the gaming-platform Kahoot! is rarely applied in medical education of histology. ${ }^{20}$ As published studies with Kahoot! and histopathology are missing until now, we are trying to integrate Kahoot in medical education of complex histopathological themes. In this pilot feasibility study, we evaluated the pros and cons of using Kahoot! in students' histo-pathological education at a medical university. Based on an immediate pre- and post-assessment procedure we intended to gain systematic experience on the feasibility of Kahoot! when used in addition to classical classroom teaching. For this purpose, different topics of pathology were presented by conventional classroom lectures (PowerPoint presentations) and additional histology slide presentations with a microscope. Before and after these lectures, the students tested their knowledge on each pathology topic using a Kahoot!-based quiz. Afterwards, the medical students had the option to evaluate this kind of educational approach by a questionnaire. In brief, the results indicate that in the context of histopathology, the use of Kahoot! proved as a feasible and easy-to-use tool to assess students' learning success that provides the basis for various statistical analyses and is well accepted by the user (ie, students).

\section{Materials and Methods \\ Participants}

As participants, the current study involved 2nd-year medical students of the Paracelsus Medical University (Salzburg, Austria). The class consisted of 51 students whose basic demographic characteristics are 23/28 female/male at a mean age of 21.6/22.7 (min. 20.1 max. 28.7) years. As the study includes no medical testing, no patient questionnaires and no epidemiological investigations no ethical vote was necessary in the authors' country. Nevertheless, the study was performed according to the Helsinki guidelines (1964). Furthermore, the study organization of the university was formlessly informed prior to starting the study and has given its approval to conduct it within the regular teaching hours reserved for pathology lectures. Before starting this educational project, all students were informed that participation was voluntary and that their decision regarding study participation would have no influence on their subsequent examinations or their medical study in general. Consent for participation and publication in a completely anonymized way was documented by an informed consent document signed by the participating students. 


\section{Procedure - Method's Design}

The methodical approach of this feasibility pilot study is presented as a flowchart in Figure 1. Using Kahoot!, the students were tested before, and after the presentation about eighteen different tumor entities of the four organ groups (i) gastrointestinal tract (GAST), (ii) skin (DERM), (iii) urogenital tract (UROG), and (iv) hematology (HEMA) on three different lecture days (see additional Table 1). The lectures consisted of a presentation and discussion of additional histological slides for each tumor entity using a demonstration microscope (Leica DM750 with ICC50 W-camera module, Leica Microsystems, Vienna, Austria). They were complemented with a Microsoft PowerPoint-based presentation about the underlying medical and pathological features of each tumor entity which included their definition, macro- and microscopical analysis. The teaching material used for the Kahoot!-based quizzes was newly compiled and students had no access to the lecture material beforehand via any of the university platforms such as Moodle.

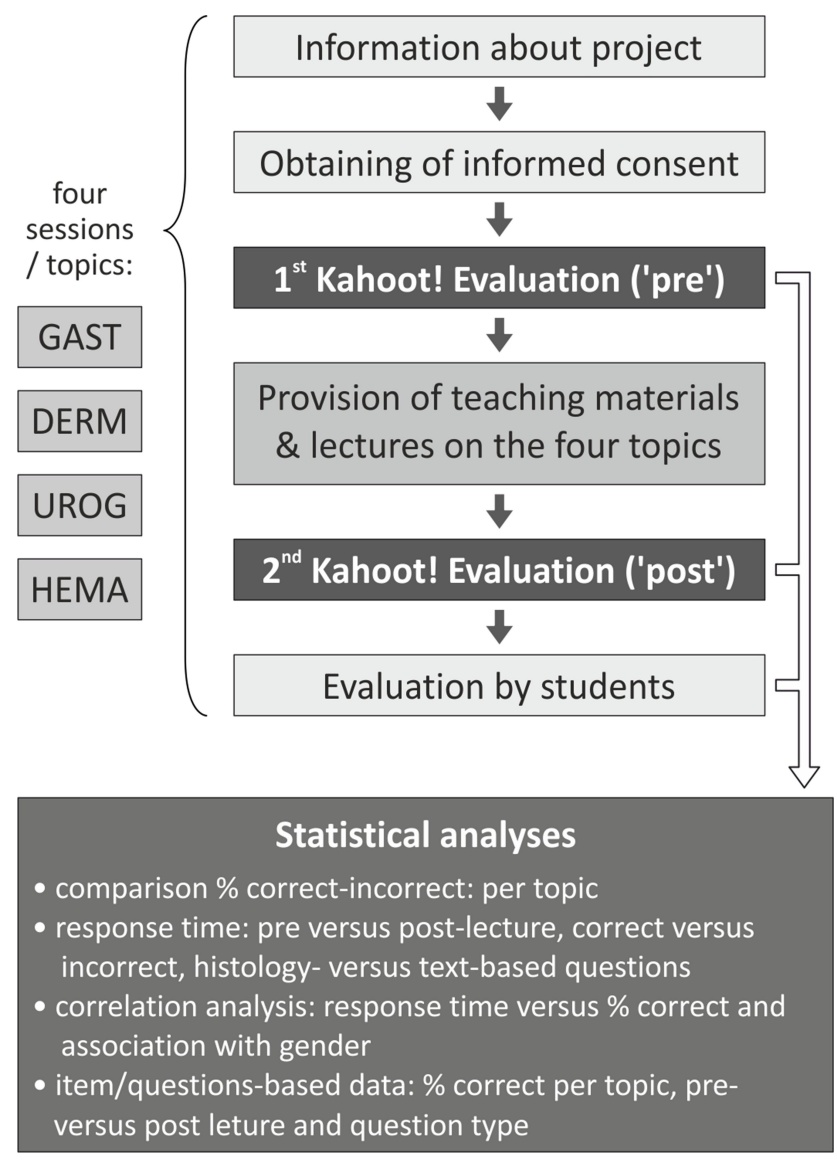

Figure I Study design. Flowchart showing the sequence of teaching and evaluation by Kahoot!. This process has been repeated for the four organ systems/topics. Abbreviations: GAST, gastrointestinal system; DERM, dermatology/skin; UROG, urogenital tract; HEMA, hematology.
Each student received an anonymous ID to grant individual access to Kahoot! within the classic game mode ("Player vs Player 1:1 Devices"). Testing with Kahoot! was performed using each the same set of questions immediately before and after the "classical" lectures. The test questions and answer choices were presented in a randomized manner (see additional Figure 1). The students had 30 seconds to pick an answer before Kahoot! automatically moved on to the next question. These question settings of Kahoot! were chosen on purpose to prevent sole memorization of the questions and the respective incorrect and correct answers. The pathological characteristics of each tumor entity were divided into two types of questions: The first set of questions was based on the histomorphological presentation ("histo") of each tumor entity and the ability to recognize them in digital images. The second set of questions was a set of text-based multiple-choice questions about the previously mentioned tumors (see additional Table 2).

After completion, students were asked to evaluate Kahoot! for its educational use in (histo-)pathology through a structured questionnaire including seven questions. This questionnaire was purpose-built to provide a quick overview on the students' previous experience with Kahoot!, its usage characteristics, and their opinion on the use of Kahoot! for (histo-)pathology lectures.

\section{Statistical Analyses}

The results provided by the Kahoot! online platform were downloaded as an XLMS-file and transferred to SPSS Statistics (version 24, IBM) and Microsoft Excel (Office Professional Plus 2016, Microsoft). These results were statistically analyzed for the percentage of correct answers, response time, and differences between the pathology topics mentioned in the beginning. The data were visualized with diagrams, using OriginPro 2020 (OriginLab Corp.), and Corel Designer 2018 (Corel Corp.). The statistical hypotheses were tested using Mann-Whitney $U$-test or Student's $t$-test after checking for normal distribution with the Kolmogorov Smirnov test and Levene's test. The correlation was calculated using Pearson's correlation analysis. A p-value of $\leq 0.05$ was considered significant.

\section{Results}

\section{Analysis of the Pre-Post-Educational Assessment with Kahoot!}

The first analysis compared the percentage of correct answers before and after evaluation with Kahoot! including all 
participants and organ systems (see Figure 2A). The analysis revealed a significant increase of the percentage of correct answers from the mean/median $47.2 / 45 \%$ before to 77.2 /
$76.3 \%$ after classroom teaching $(\mathrm{p}<0.001)$. Only students who participated in the pre- and post-lecture tests (in any of the four organ systems) were included in the evaluation in
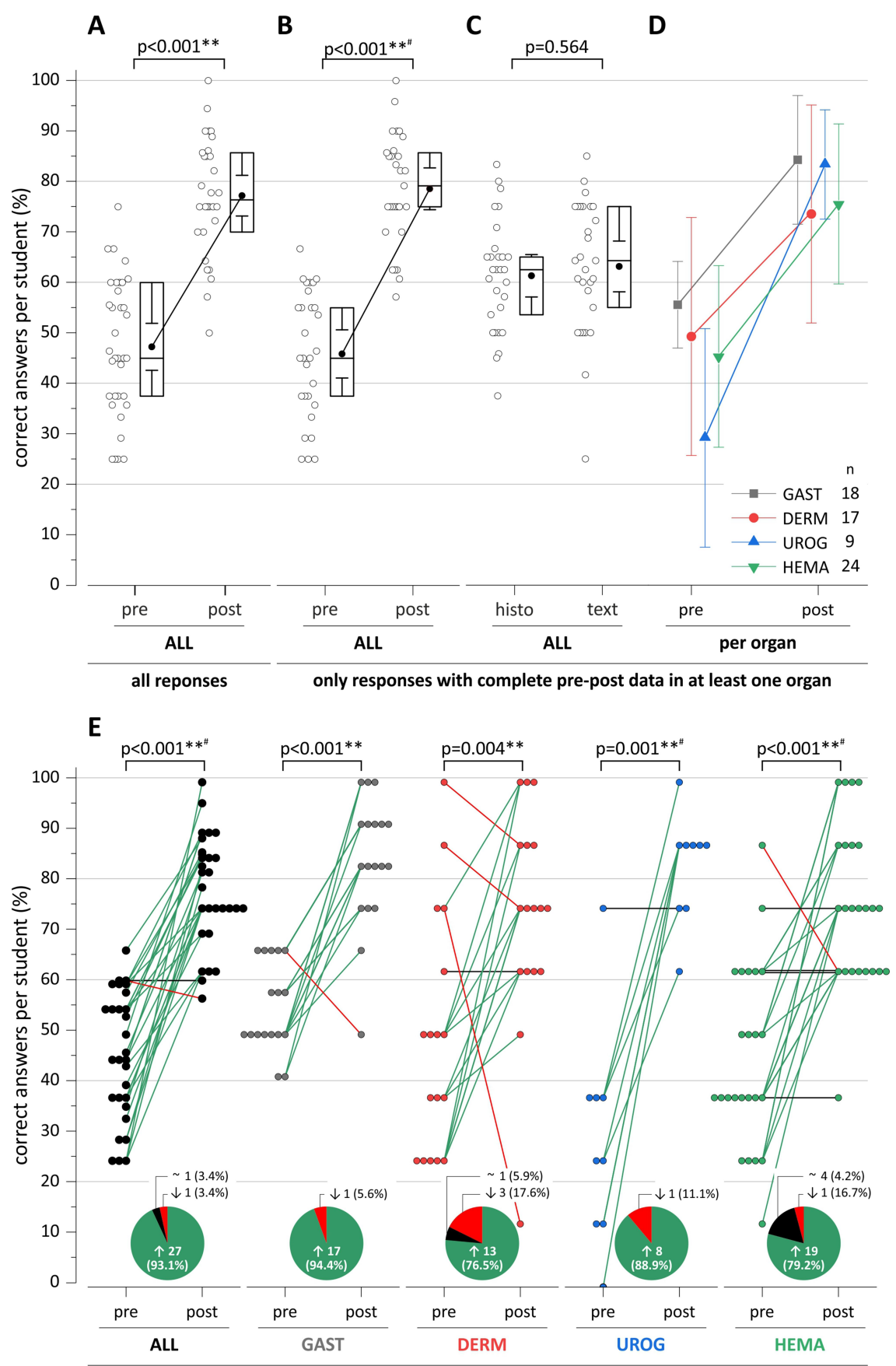

only responses with complete pre-post data in at least one organ

Figure 2 Data analysis of student-based results. (A) Pre-post-analysis of the percentage of correct answers including all available results (ie including cases where individual students participated in either pre- $(n=35)$ or post- $(n=30)$ evaluation). (B) Same as $A$, but only including students with complete pre- and post-answers ( $n=29)$ in one or more organs. All subsequent figures and analysis contain only "complete data sets", ie data from students having participated in both, pre- and post-evaluation by Kahoot! in one or more organs. (C) Comparison of \% correct answers between histology- and text-based Kahoot! questions. (D) Comparison of the percentage of correct answers pre and post-lecture for each individual topic (mean \pm standard deviation). (E) Analysis of pre/post results on the students' level. Each participating student is represented by a filled circle that is connected by straight lines between pre and post status: students with improved, stable or worse results are indicated by green, black and red lines, respectively. The pie chart inserts show the proportion of students (for all respective the individual topics) and how their results (percentage of correct answers) have changed pre and post-lecture. Differences between groups were calculated by $t$-tests (for normally distributed data) or Mann-Whitney-tests in case of data without normal distribution (indicated by \#); **Indicates $\mathrm{p}<0.01$. 
order to yield comparable results (Figure 2B and D). The comparison of histology- and text-based questions slightly favored text-based questions with a higher increase in correct answers (not significant, $\mathrm{p}=0.564$; Figure $2 \mathrm{C}$ ). Similar to the overall analysis (Figure 2A and B), for each pathological sub-topic, a significant improvement of the percentage of correct answers could be observed, while the urogenital tract system showed the steepest slope between pre- and post-lecture (see Figure 2D and E). On average, only one student failed to improve his/her score while the other 27 students achieved an improvement after the lecture. Similar results were found within each organ system (organs; Figure 2E): a clear majority of students (76-94\%) improved their results whereas few students gave less correct answers after the lecture.

\section{Analysis of Response Time}

The average response time for pre- and post-assessment with Kahoot! decreased significantly in the overall comparison ("ALL" from mean/median 9.1/8.3 seconds in the pre-assessment to $5.1 / 4.3$ seconds in the post-assessment; Figure 3A). Similar results were obtained within each topic $(\mathrm{p}<0.001)$. Interestingly, the answering speed was significantly higher for correct than for incorrect answers, again for all questions as well as for the topic-specific questions (Figure 3B, p<0.001). Further (Figure 3C), the response time was not significantly different between histology- and text-based questions. Significant differences were observed for gastrointestinal or hematological topics with opposite effects $(p<0.002)$. No correlation was found between the percentage of correct answers and answering speed of the students (see Figure 3D). Gender had no significant impact on the overall response time. Female students showed a (insignificant, $\mathrm{p}=0.327$ ) trend towards faster responses than male students in the pre-lecture assessment (Figure 3E).

\section{Quality-Analysis of the Developed Test-Items}

Figure 4A represents the percentage of correct answers for each 18 text- and histology-based question tests presented with Kahoot! with a target score ranging from $20 \%$ to $80 \%$ of correct answers per test (not too easy and not too difficult). Three histology-based questions were too difficult compared to one text-based question, whereas two text-based questions were too easy in the pre-education assessment.
After the lecture, a general shift towards more correct answers (over 80\%) was observed independently of the question set (histology vs text). Considering the distribution of percentage of correct answers per question set before and after lectures, a clear shift of the distribution's skewness from slightly right $(0.126)$ to the left side $(-0.850)$ was observed (Figure 4B), indicating a shift of the fitted normal distribution towards a "better" results post-lecture.

In order to provide first information on possible beneficial learning effects of using Kahoot! in pathology lectures, we analyzed the exam results of the students included in the current study (year 2019) versus students' results from 2018 (without Kahoot!). Both exams were electronic exams in Moodle using multiple choice and USMLE-like questions. Our results show that the students of year 2019 performed on average better: they scored $2.5 \%$ better while they needed $6.4 \mathrm{~min}$ less time to complete the exam (see Figure 6). Thereupon we analyzed the performance of students from year 2019 in relation to their participation in the Kahoot! sessions (complete vs incomplete). The statistical analysis revealed no significant difference; however, the students with complete sessions showed a tendency for better results (interquartile range complete of $96.5-100$ versus

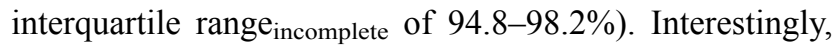
the students with complete sessions were significantly slower in finishing the exam (mean time complete $=24.7 \mathrm{vs}$ mean time $_{\text {incomplete }}=19.2$ minutes).

\section{Student Evaluation of the Kahoot! Project in Pathology Education}

Finally, all participating students had the opportunity to feedback on this educational project (summarized in Figure 5). Overall, the majority of the students (70\%) did not know about Kahoot! before this research project. Most students found the examination platform user friendly and easy to access with smartphones, while the allotted time was found appropriate to make an answer choice (Figure 4B). In regards of the didactic value of Kahoot! in the field of pathology, most students considered it very good as a supplementary tool to strengthen the lectures' content and for knowledge testing (Figure 5C).

\section{Discussion}

Online gamification platforms will be used increasingly as digital tools in the medical education. ${ }^{6,10,11}$ The 

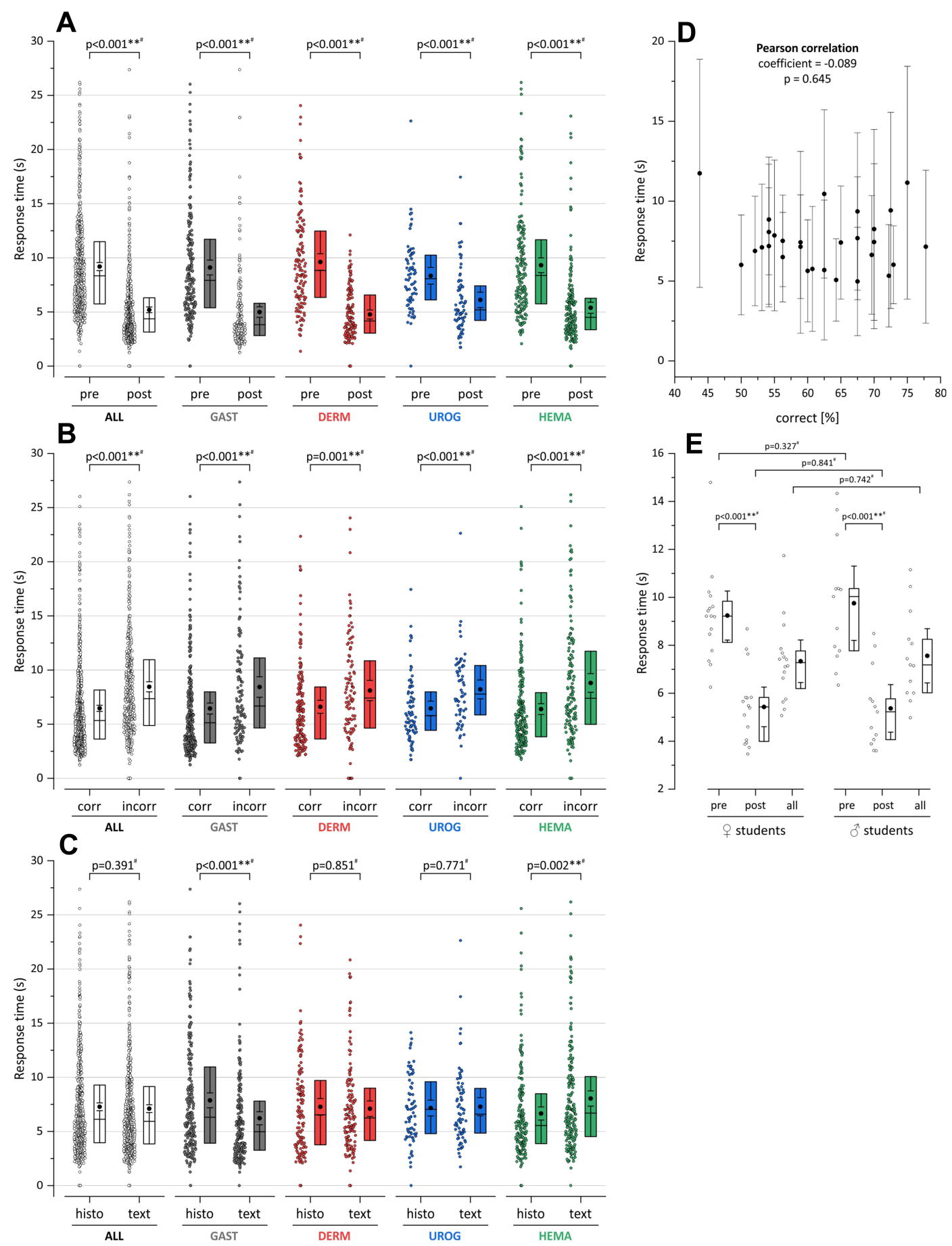

Figure 3 Analysis of the Kahoot! response time per student. (A) The response time for the individual topics and for all topics together ("ALL") is compared pre and postlecture. (B) Correct and incorrect answers are compared. (C) Histology- and text-based questions are compared. (D) Correlation analysis of response time (y-axis) versus percentage of correct answers. (E) Comparison between female and male students regarding pre, post and overall response time. Box plots show the mean (filled circle), median (horizontal line), 25/75\% quartiles (box) and the 95 confidence interval (whiskers). Differences between groups were calculated by $t$-tests (for normally distributed data) or Mann-Whitney-tests in case of data without normal distribution (indicated by \#); **Indicates $p<0.01$.

enormous digital innovations in medicine will produce new powerful opportunities for medical education. Additionally, it could be empirically demonstrated that gaming may be more effective than traditional teaching methods ${ }^{12,13}$ due to increased student motivation and engagement. ${ }^{14,21}$ The difficulty for faculty and administration is the selection of an adequate platform and integration into a curriculum in order to increase retained 
A

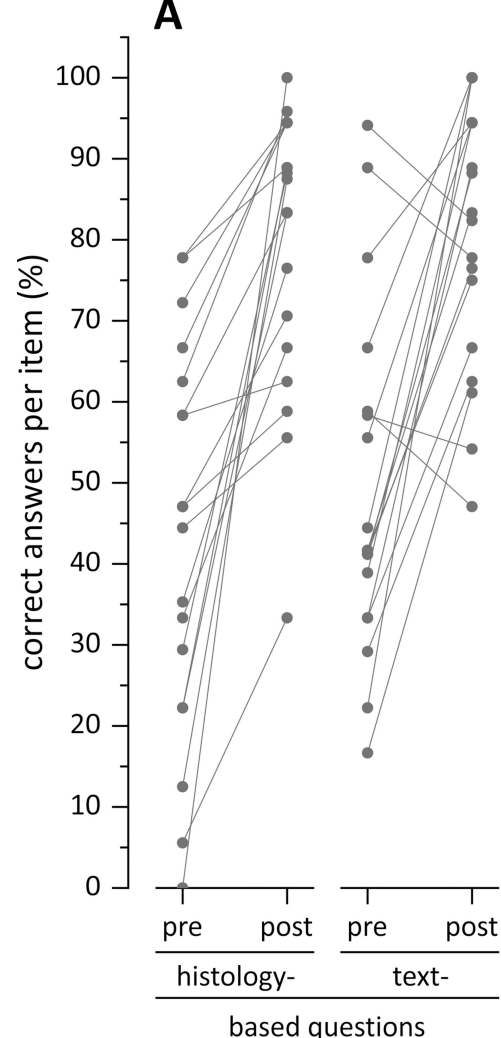

B

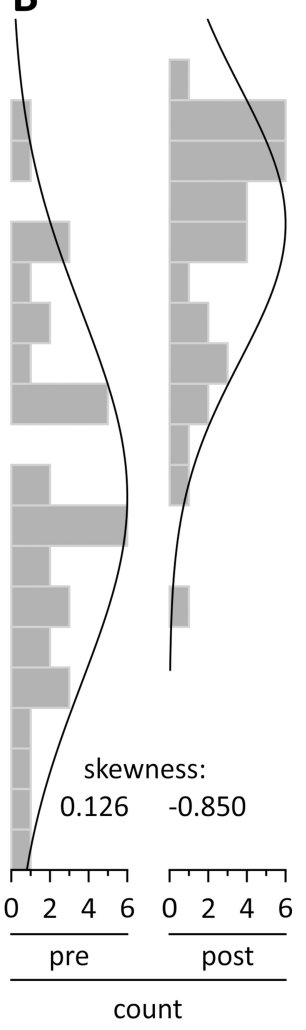

Figure 4 Analysis of the Kahoot! questions (items). (A) The percentage of correct answers is shown per question (item) between pre versus post for the two question types (text- or histology-based). Lines connect the pre/post results obtained for each question. (B) Histograms indicating the (shift) of distribution for the pre/post percentage of correct answers per item. The solid line indicates a normal distribution.

information and gain more competency as beginning medical professionals. ${ }^{22,23}$ A promising approach is the Bauman's layered-learning model describing the connection of a traditional didactic presentation with multimedia educational technologies. ${ }^{24}$ The number of published works is large regarding with different aspects of Kahoot! for teaching, learning, and assessment in school and university as well in medical education. ${ }^{20,25-33}$ Accordingly, the key messages of these published articles is that (i) Kahoot! web-based interactive gaming is mostly perceived as a valuable active learning strategy for different subjects by the students, that (ii) Kahoot! could consecutive increase motivation and engagement based on a included time-to-respond scoring system. Due to the lack of studies specifically addressing the potential benefits of Kahoot! in (histo-)pathology education, we analyzed the feasibility of Kahoot! in combination with regular, less interactive medical education including lectures and interactive microscopy sessions.

A

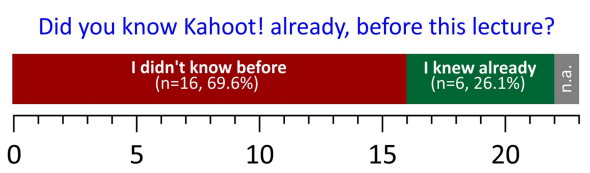

B

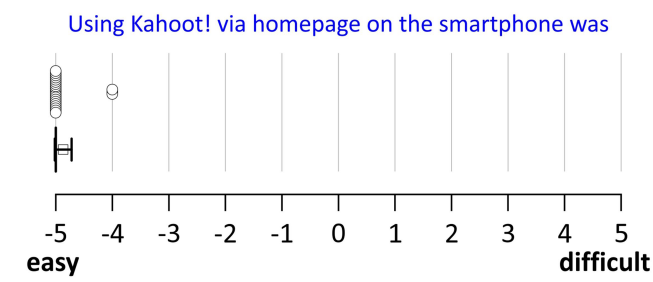

The time provided for aswering the Kahoot! questions was

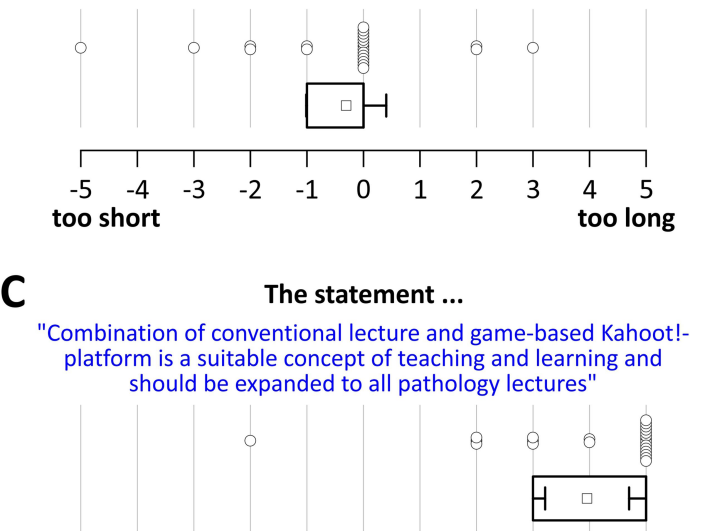

"By using Kahoot! the teaching content has been strengthened"

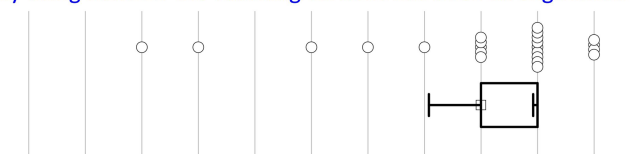

„Kahoot! is an appropriate method for non-immanent knowledge-tesing in pathology"...

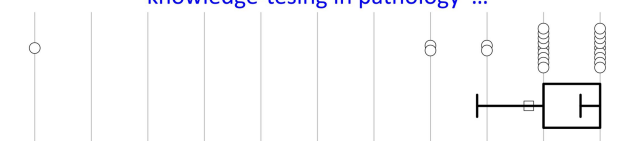

„The content of the Kahoot! questions was conceptually and substantially adjusted to the corresponding teaching content"

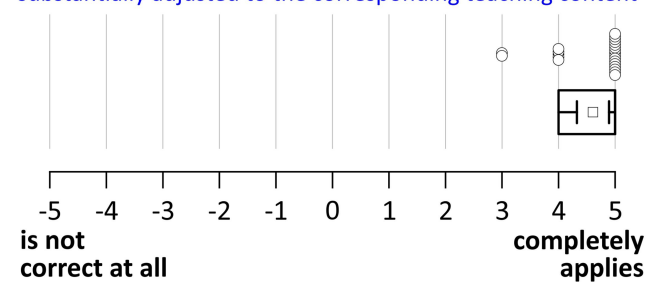

Figure 5 Student's evaluation of the Kahoot!-supplemented pathology education. (A) Number and percentage of students who knew (or did not know) Kahoot! before this project. (B) Usability of the chosen Kahoot! settings. (C) Student's answers on suitability, practicability and design of the Kahoot!-supplemented pathology lectures. Box plots show the mean (filled circle), median (horizontal line), 25/ $75 \%$ quartiles (box) and the 95 confidence interval (whiskers).

\section{Testing Results Before and After Medical Education with Kahoot!}

Our study demonstrates the feasibility of digital medical education in pathology in relation to (histo-) pathological 

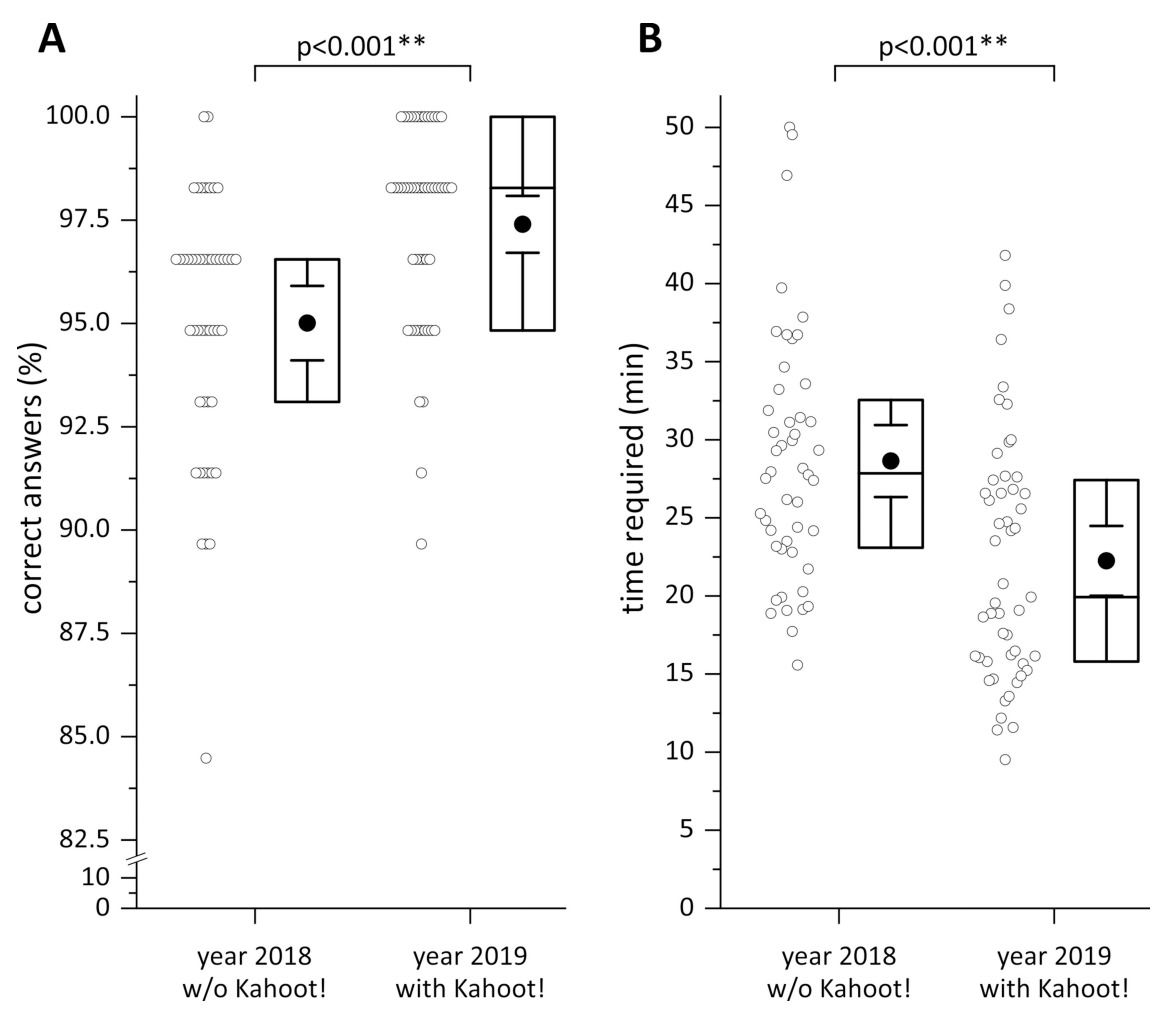

Figure 6 Comparison of students' results in final exam. The percentage of correct answers (A) and the time required to complete the test (B) is shown for 2018-year students (without Kahoot!) and 2019-year students (with Kahoot!). Box plots show the mean (filled circle), median (horizontal line), 25/75\% quartiles (box) and the 95 confidence interval (whiskers). **Indicates $\mathrm{p}<0.01$.

Abbreviation: w/o, without.

topics of different organ systems through text- and histological-based questions as well as of statistical potency of pre-post-assessment. Overall, Kahoot! could be used for assessment of pathological subjects in the education of medical students, with significant learning success increase upon education using the game-based learning platform Kahoot!. This was also evident for histomorphological and theoretical questions, when evidently test scores for text-based question were slightly higher, indicating the difficulty of morphological interpretation for medical students. ${ }^{30}$ Further, response time was significantly reduced, implying educational efficiency. Simultaneously, this educational strategy provides a first feedback for upcoming exams such as the United States Medical Licensing Examination (USMLE), which is required to take in the medical curriculum of the Paracelsus Medical University. Only minor gender differences were observed throughout the study. All these demonstrated results were comparable to similar projects using Kahoot! Felszeghy et al implemented the gamebased platform Kahoot! in the medical and dental histology course and demonstrated a significant increase in correct test answers from before to after conventional teaching (from about $70 \%$ before to about $90 \%$ after teaching sessions). ${ }^{20}$ Interestingly, team-mode showed better scoring in comparison to individual mode of Kahoot! in the study design of Felszeghy. Other investigations using Kahoot! for medical education could confirm, that Kahoot! supports medical education in several and diverse medical fields such as pharmacology, nursing, anatomy and physiology by increasing motivation and engagement as a fun tool. ${ }^{25,26,29,31,32}$ The analysis of Kahoot! scoring improvement and the time to respond could demonstrate improvements in the understanding, progression, and knowledge increase of medical students. ${ }^{27,28}$

\section{Statistical Method to Analyze Results Data of Kahoot!}

The data with descriptive observations collected by Kahoot! were automatically saved, archived and could easily be accessed and downloaded every time, similar to other online-gaming tools like Quizziz and Socrative. The data sets were categorized into overall results and in detail for each question. As the data sets require manual transfer/ 
import to statistical programs such as SPSS, generating detailed response analyses requires considerable efforts. Furthermore, a tool to directly contrast pre- and postlecture scores should be included to have an automatic comparison. Altogether, while raw data on response behavior are available from the Kahoot! platform for various statistical analyses, a free implementation of some basic statistical issues in Kahoot! is desirable to facilitate such analyses.

The participating year 2019 students showed a significant better outcome at the final exam, compared to the preceding year's (2018) students which had comparable demographic characteristics. This might be related to a more intensive education combined with the Kahoot! motivation. Interestingly, however, within the students of 2019, no significant positive effect of having participated in the Kahoot! sessions on the outcome of the final exam could be detected.

\section{Student Evaluation of the Role of Kahoot! in Medical Education}

The results of the user-experience questionnaire were very positive. Beside the high ease of use of Kahoot!, the students convincingly recommended Kahoot! as an appropriate method for pleasant knowledge testing. Therefore, most students declare that a combination of conventional lectures and game-based platforms like Kahoot! should be routinely implemented for all pathology lectures in the future to strengthen the teaching success. This formative assessment is in harmony with previous studies underlining the students ' acceptance of gaming tools for medical education in addition to classical educational methods. ${ }^{14,20,27}$

Based on the feedback provided through the questionnaire, the students generally support to integrate Kahoot! in medical (pathology) education. Both, the aspects of technical performance (using smartphones) and didactic purposes of using Kahoot! in (histo-)pathology classroom teaching for real-time assessment were rated very positive by the respondents. Besides attempts to increase efficiency and attractiveness of medical education by implementation of new electronic tools, more traditionally minded students, however, also want additional printed or written material such as text books or digital resources provided by the teachers. ${ }^{20}$ In summary, the application of Kahoot! in the medical education could successfully combine classical textbooks and non-interactive lectures to enhance the learning outcome for upcoming medical school classes. ${ }^{6}$
Other acceptance analysis on Kahoot! showed that gaming could enhance the motivation of the students, which was not part of this study. Interestingly, a recent educational investigation could show that the student preferences of active learning is higher than classical teaching, where the fill-in-the-blank activities and videos were more effective in the exam performance in comparison to Kahoot!, ${ }^{33}$ raising the question of how to achieve the best mix of traditional resources and active learning strategies.

Some methodological limitations of the presented educational study using Kahoot! in medical education were obvious and need to be mentioned: a) Due to the pilot character of the current pilot study in (histo-)pathology, no explicit control group has been defined and analyzed in parallel. Subsequent studies should, therefore, investigate the learning outcome assessed by Kahoot! versus conventional post-lecture examination alone. b) The chosen test scenario evaluates only the short-term memory of the student. Other approaches are needed to test intermediate and/or long-term memory. c) The results of the pre- and postassessment could be influenced by a short temporal distance of four hours and memory of specific items. This effect could not be excluded. However, this would demand the percentage of correct answers in the post-assessment to reach $100 \%$ which is not the case in our study. Furthermore, the chosen test settings of Kahoot! include randomization for both: The questions and possible answers, in order to avoid such short memory effect. d) The prior knowledge of the students about the pathological topics has not been evaluated and integrated in the statistical analysis. Nevertheless, all course materials were newly designed and were not accessible for students prior to the lectures. e) Since participation in the study was voluntary, not all students participated in the project and only results of students with complete pre- and post-answers were analyzed, therefore limiting the statistical strength of this study. Furthermore, due to the university's student-centered teaching approach, the class size was a priori limited. f) An evaluation of the performance and acceptance of Kahoot! in comparison to other online gamification platforms like Quizziz, Quizlet and Socrative was not performed, because this was not the primary intention of the presented study. It appeared that Kahoot! is more user-friendly to our students than other platforms, which is a subjective standpoint. ${ }^{14}$

\section{Conclusion}

In summary, the online gaming-platform Kahoot! can easily be introduced in the medical education in the various fields of pathology. Whether Kahoot! should be used 
alone or in combination with classical education, must be evaluated in further studies. Retrospectively, the teachers get a good overview of the learning curve through the test results. Finally, the students' acceptance of Kahoot! was very high, indicating the educational potency of the online gamification platform as an additional part in the classical medical education. Therefore, we consider real-time assessment using Kahoot! (or other comparable tools) as feasible and efficient to increase students' engagement and motivation for active participation during classroom teaching of pathology topics.

\section{Abbreviations}

DERM, dermatology/skin; GAST, gastrointestinal system; HEMA, hematology; UROG, urogenital tract.

\section{Acknowledgment}

The authors thank all medical students of the study year 2017 of the Paracelsus Medical University (Salzburg, Austria) having participated in this study. Additionally, we thank Lukas Winkelmann, Leonard Dinkelacker and Tanja Hartmann for discussion and proofreading of the manuscript. The authors declare that no explicit funding was used for conducting this study.

\section{Disclosure}

The authors report no conflicts of interest in this work.

\section{References}

1. Zavlin D, Jubbal KT, Noe JG, Gansbacher B. A comparison of medical education in Germany and the United States: from applying to medical school to the beginnings of residency. GMS J. 2017;15:Doc15.

2. Berr F, Ponchon T, Neureiter D, et al. Experimental endoscopic submucosal dissection training in a porcine model: learning experience of skilled Western endoscopists. Dig Endosc. 2011;23(4):281-289. doi:10.1111/j.1443-1661.2011.01129.x

3. Khan AA, Siddiqui AZ, Mohsin SF, Momani MMA, Mirza EH. Impact of network aided platforms as educational tools on academic performance and attitude of pharmacology students. Pak J Med Sci. 2017;33(6):1473-1478. doi:10.12669/pjms.336.13290

4. Maske SS, Kamble PH, Kataria SK, Raichandani L, Dhankar R. Feasibility, effectiveness, and students' attitude toward using WhatsApp in histology teaching and learning. J Educ Health Promot. 2018;7:158.

5. Nicola S, Stoicu-Tivadar L. Mixed reality supporting modern medical education. Stud Health Technol Inform. 2018;255:242-246.

6. Bigdeli S, Kaufman D. Digital games in medical education: key terms, concepts, and definitions. Med J Islam Repub Iran. 2017;31(1):52. doi: $10.14196 / \mathrm{mjiri} .31 .52$

7. Johnson D, Deterding S, Kuhn KA, Staneva A, Stoyanov S, Hides L. Gamification for health and wellbeing: a systematic review of the literature. Internet Interv. 2016;6:89-106.

8. McDougall A. When i say ... gamification. Med Edu. 2018;52 (5):469-470. doi:10.1111/medu.13481
9. Looyestyn J, Kernot J, Boshoff K, Ryan J, Edney S, Maher C. Does gamification increase engagement with online programs? A systematic review. PLoS One. 2017;12(3):e0173403. doi:10.1371/ journal.pone.0173403

10. Latham B, Poyade M, Finlay C, Edmond A, McVey M. New tools in education: development and learning effectiveness of a computer application for use in a university biology curriculum. $A d v$ Exp Med Biol. 2019;1138:29-46.

11. Richmond H, Copsey B, Hall AM, Davies D, Lamb SE. A systematic review and meta-analysis of online versus alternative methods for training licensed health care professionals to deliver clinical interventions. BMC Med Educ. 2017;17(1):227. doi:10.1186/ s12909-017-1047-4

12. Pettit RK, McCoy L, Kinney M, Schwartz FN. Student perceptions of gamified audience response system interactions in large group lectures and via lecture capture technology. BMC Med Educ. 2015;15 (1):92. doi:10.1186/s12909-015-0373-7

13. Boeker M, Andel P, Vach W, Frankenschmidt A, Szolnoki A. Game-based e-learning is more effective than a conventional instructional method: a randomized controlled trial with third-year medical students. PLoS One. 2013;8(12):e82328. doi:10.1371/journal.pone.0082328

14. Ismail MA, Ahmad A, Mohammad JA, Fakri N, Nor MZM, Pa MNM. Using Kahoot! as a formative assessment tool in medical education: a phenomenological study. BMC Med Educ. 2019;19(1):230.

15. Wang AI, Tahir R. The effect of using Kahoot! for learning a literature review. Comput Educ. 2020;149.

16. Yang BW, Razo J, Persky AM. Using testing as a learning tool. $\mathrm{Am}$ J Pharm Educ. 2019;83(9):7324. doi:10.5688/ajpe7324

17. Burgess A, Mellis C. Feedback and assessment for clinical placements: achieving the right balance. Adv Med Educ Pract. 2015;6:373-381. doi:10.2147/AMEP.S77890

18. Tormey W. Education, learning and assessment: current trends and best practice for medical educators. Ir J Med Sci. 2015;184(1):1-12. doi:10.1007/s11845-014-1069-4

19. Kibble JD. Best practices in summative assessment. Adv Physiol Educ. 2017;41(1):110-119. doi:10.1152/advan.00116.2016

20. Felszeghy S, Pasonen-Seppanen S, Koskela A, et al. Using online game-based platforms to improve student performance and engagement in histology teaching. BMC Med Educ. 2019;19(1):273. doi:10.1186/s12909-019-1701-0

21. Fuster-Guillo A, Pertegal-Felices ML, Jimeno-Morenilla A, AzorinLopez J, Rico-Soliveres ML, Restrepo-Calle F. Evaluating impact on motivation and academic performance of a game-based learning experience using kahoot. Front Psychol. 2019;10:2843. doi:10.3389/ fpsyg.2019.02843

22. Rojas D, Kapralos B, Dubrowski A. The role of game elements in online learning within health professions education. Stud Health Technol Inform. 2016;220:329-334.

23. Kuipers DA, Terlouw G, Wartena BO, van 'T Veer JT, Prins JT, Pierie JPEN. The role of transfer in designing games and simulations for health: systematic review. JMIR Serious Games. 2017;5(4):e23. doi:10.2196/games.7880

24. Baumann EB. Games, virtual environments, mobile applications and a futurist's crystal ball. Clin Simul Nurs. 2016;12(4):109-114. doi:10.1016/j.ecns.2016.02.002

25. Barnes R. Kahoot! in the classroom: student engagement technique. Nurse Educ. 2017;42(6):280. doi:10.1097/NNE.0000000000000419

26. Bryant SG, Correll JM, Clarke BM. Fun with pharmacology: winning students over with Kahoot! game-based learning. J Nurs Educ. 2018;57(5):320. doi:10.3928/01484834-20180420-15

27. Castro MJ, Lopez M, Cao MJ, et al. Impact of educational games on academic outcomes of students in the degree in nursing. PLoS One. 2019;14(7):e0220388. doi:10.1371/journal.pone.0220388

28. Dell KA, Chudow MB. A web-based review game as a measure of overall course knowledge in pharmacotherapeutics. Curr Pharm Teach Learn. 2019;11(8):838-842. doi:10.1016/j.cptl.2019.04.012 
29. Jamil Z, Fatima SS, Saeed AA. Preclinical medical students' perspective on technology enhanced assessment for learning. J Pak Med Assoc. 2018;68(6):898-903.

30. Johnson S, Purkiss J, Holaday L, Selvig D, Hortsch M. Learning histology - dental and medical students' study strategies. Eur J Dent Educ. 2015;19(2):65-73. doi:10.1111/eje.12104

31. Kuo CL, Chuang YH. Kahoot: applications and effects in education. Hu Li Za Zhi. 2018;65(6):13-19.
32. Solis de Ovando A, Rodriguez A, Hullin C. Digital game-based learning: a didactic experience in the pre-degree nursing career. Stud Health Technol Inform. 2018;250(88).

33. Sumanasekera W, Turner C, Ly K, Hoang P, Jent T, Sumanasekera T. Evaluation of multiple active learning strategies in a pharmacology course. Curr Pharm Teach Learn. 2020;12(1):88-94. doi:10.1016/j. cpt1.2019.10.016

\section{Publish your work in this journal}

Advances in Medical Education and Practice is an international, peerreviewed, open access journal that aims to present and publish research on Medical Education covering medical, dental, nursing and allied health care professional education. The journal covers undergraduate education, postgraduate training and continuing medical education including emerging trends and innovative models linking education, research, and health care services. The manuscript management system is completely online and includes a very quick and fair peer-review system. Visit http://www.dovepress.com/testimonials.php to read real quotes from published authors. 